\title{
Plotting, Improvisation, and Anthony Trollope
}

'He was the great improvvisatore of these latter years', Henry James declared of Anthony Trollope, in an essay written a few months after the older novelist's death. ${ }^{\mathrm{I}}$ This characterisation occurs midway through a notorious passage about Trollope having 'published too much [...] [and] sacrificed quality to quantity', supported by the account of a transAtlantic voyage he had shared with a younger James, who witnessed firsthand how 'Every day of his life he wrote a certain number of pages of his current tale [...] Trollope shut himself up in his cabin every morning [...] [and] drove his pen as steadily on the tumbling ocean as in Montague Square. ${ }^{2}$ Embedded within what James Kincaid has called 'James's terribly effective propaganda' or 'myth-making' of Trollope as a narrative manufacturer rather than (as James conversely implies for himself) a technical artist, the fleeting figure of the 'improvvisatore' has often been swallowed up by the force of this broader rhetorical sweep. ${ }^{3}$ Little to no comment has therefore been made about the oddness and specificity of an analogy that compares the English novelist, generating manuscripts of distinctly unlyrical prose in a private cabin, with a type of Italian folk performer, traditionally known for extemporising verse in live performances on the street or stage. Within this analogy lies James's more ambivalent encounter - much like Gaskell's with the Brontë juvenilia - with a 'tumbling', playful mode of novel-writing vastly different from his own.

Like Gaskell, James is ambivalent about praising an aptitude for invention - a talent for making things up - which, if obviously necessary to novel-writing, is not so usually commended as a distinction of the novelist as, for instance, their powers of truthfulness or expression. '[W] have no English word for a talent which in England is unknown', Anna Jameson writes in her I 826 novel The Diary of an Ennuyée, describing a series of seven 'improvvisazion[i]' by the Roman performer Bartolomeo Sestini, each spontaneously composed on topics offered by the audience, with new key words and rhymes suggested moment-to-moment and 
incorporated in time to an accompanying musical beat. ${ }^{4}$ The Penny Magazine's I839 article on 'The Improvvisatori' similarly extols their ability to compose within impromptu conditions:

Mr. Rose speaks of seeing a man to whom three subjects for sonnets were proposed: one of which was Noah issuing from the Ark; another, the death of Caesar; the third, the wedding of Pantaloon. They were to be declaimed interlacedly; that is, a piece of Noah, then a piece of Caesar, then a piece of Pantaloon: returning after that for another piece of Noah, and so on. Nor were these difficulties enough; he was also to introduce a particular verse specified by one of the audiences at a particular place in each sonnet. He accomplished this task in ten minutes. ${ }^{5}$

If it takes remarkable skill to produce 'a certain number of pages' every day given the contingencies of circumstance and composition, especially while (as Trollope was known to do) interlacing multiple plots and novels at once, this may be a feat more striking in its performance than its results. Admirers of the improvvisatore commonly mount this as a defence of the improvised text: 'these extemporaneous effusions ought to be judged merely as what they are', Jameson argues, 'not as finished or correct poems, but as wonderful exercises of tenacious memory, ready wit, and quickness of imagination'. ${ }^{6}$ Moreover, as with other improvisational arts like live jazz or freestyle rap, the work of the improviser appears arbitrary in form and subject - using whatever rhyme, metre, theme, or stipulation suggested by the audience - when reviewed apart from the artificial logic of its performance. To have witnessed Trollope's novel-writing may have been a more meaningful experience than reading his novels, recalling an essentially performative tradition at work in a genre James primarily valued for its 'finished or correct' form.

This chapter proposes improvisation as a fundamental characteristic of Trollope's fiction, an ad hoc art of the novel to which he repeatedly confessed in his autobiography: 'I never found myself thinking about the work that I had to do till I was doing it [...] trusting myself, with the narrowest thread of a plot, to work the matter out when the pen is in my hand' ( $A A$ I 45 ). If we continue to lack the critical terms for a talent which has been undervalued in the novel, which might seem unsuitable for the form as we know it, paracosmic play can provide a heuristic for understanding and appreciating the uses of inventive spontaneity. Fiction, too, has an artificial logic: in his account of play, De Quincey describes the creative plotting with which he evaded or worked around the narrative traps set by his sibling, a form of authorial ad-libbing he compares to a lawyer's creative interpretation of facts. These manoeuvres obey and 
depend on the strict consistency yet explicit subjectivity of fictional information, a malleability which characterises the nature of facts in both imaginary worlds and novels. If an Angrian duchess's death is later shown to have been misreported, or the Gombroonians are suddenly revealed to have tails under their togas, or Mrs Proudie dies from an unsuspected heart condition, these twists might be news even to the authors themselves (who have just now thought them up), but in the absence of previous statements to the contrary, can be newly established as having always been true. Only an imaginary world affords this open-ended view of facts, and only an improviser's perspective can appreciate the possibilities of a fiction never finished or correct, but accumulated and adjusted.

At stake in the idea of an improvised novel is the question James poses elsewhere to the nineteenth-century novel as a whole: what do such fictions, 'with their queer elements of the accidental and the arbitrary, artistically mean?'7 As I have argued, acknowledging the inherent arbitrariness of novel fiction can reveal new ways of performing and interpreting artistic meaning or function - in this chapter, I propose how emphasising the flexibility of fictional realities can reveal a different mechanism by which Trollope realises his reputation as an ethical novelist. If the representation of moral reasoning through fiction is often lauded as the sympathising, exemplary, or improving function of the realist novel, the practice of moral reasoning as fiction is conversely deeply suspicious. Certain types of people are particularly adept at what we sometimes call 'mental gymnastics', the too-flexible interpretations of fact or logic by which individuals arrive at specious, often self-serving conclusions - politicians, lawyers, propagandists, and so on - but also arguably improvisers, novelists, and literary critics, all of whom require a creative relation to their materials, turning unexpected results out of seemingly determined situations. If we consider ingenuity and skill to be inappropriate forms of response to ethical dilemmas, then the performance of such dilemmas in Trollope's fiction appear especially unsuitable as moral examples, because (as James suggests through the improviser) their value lies in the inventive but arbitrary working-out of made-up problems. But as the right conclusion is emphatically not the point of a gymnastics routine, is it possible to appreciate a novel's deliberately convoluted performance of ethical explanation and judgement? What does it mean for moral reasoning to be a spectator sport?

Examining cases of how characters in The Small House escape their moral quandaries, I argue that their diegetic decision-making is mirrored by the extradiegetic process of Trollope's writing, connected in the same 
endeavour 'to work the matter out' as it happens on the level of ethical choice and of narrative plot. Trollope and his characters plot solutions to moral dilemmas as if (or in the author's case, knowing) that the facts of the situation are on some level arbitrary - just a story, only pretend, explicitly artificial - and therefore open to reinterpretation. Understanding ethical deliberation as narrative invention, a specious manipulation of truths within the arbitrary world of a novel, does not diminish its responsibility but cultivates a moral perspective by other means than through exemplariness or didacticism. Improvised play, a practice of acting within the possibilities of accidental conditions, is intrinsic to the aesthetics of Trollope's novels and to their understanding of moral agency. In what follows, I propose the deliberate values of flexibility, ingenuity, and spontaneity afforded by how lightly Trollope takes the novel.

\section{Contriving the Novel}

Everything would work out, the narrator suggests midway through Barchester Towers, if only Eleanor Bold would cry in front of Mr Arabin: 'he would have melted at once, implored her pardon, perhaps knelt at her feet and declared his love. Everything would have been explained [...] But then where would have been my novel? She did not cry, and Mr Arabin did not melt'. ${ }^{8}$ If some measure of contrivance is necessary to novelwriting (in the sense of being made up, all novels are contrived), the open acknowledgement of this necessity is a particular signature of Trollope's narration. In justifying the continuation of the narrative conflict, he appeals not to the psychological rationale of the characters - that this is how Eleanor would act when suffering an unjust accusation - but to the artificial logic of plot, the misunderstandings which could be spared were they not indispensable for the story to continue. As James points out, 'many more specimens' exist in Trollope's oeuvre of these 'little slaps at credulity', which he deplores as 'very discouraging [...] even more inexplicable; for they are deliberately inartistic'. 'The second chapter of Orley Farm likewise reassures us that the middle-aged Lady Mason, recently introduced, is 'not intended to be the heroine. The heroine, so called, must by a certain fixed law be young and marriageable'. ${ }^{\text {Io }}$ As Kincaid rhetorically suggests, this sentence seems to exemplify an 'attachment to romantic comedy formulas, an attachment apparently so fixed that those formulas are shamelessly duplicated [...] who so set the law? And if one indeed determines to obey this law, why call our attention to it and thus increase its unnaturalness and diminish its force?' ${ }^{\mathrm{II}}$ 
The facts and realities of Trollope's narratives often resist a naturalistic explanation (being made explicable on the level of the purely diegetic), but instead suggest metaleptic references to extradiegetic conditions (literary convention or authorial convenience) which rationalise them through an explicit logic of fiction. Even if such statements are to some extent ironic, they represent a different order of irony, for instance, to truths universally acknowledged about single men with good fortunes. When Trollope mocks the rules of his characters' world, he reveals that such a world is not only governed by social or natural laws but also subject to the practical rules of fiction-writing. The world of the novel is arbitrary, not only in the sense that social realities are arbitrary, but in the way that imaginary worlds are. For Kincaid, this anti-mimetic streak presents a problem for the seriousness of Trollope's purpose and the moral weight of his task, as calling attention to the 'unnaturalness' of narrative might diminish its relevance as an account of life. As James formulates the problem:

[Trollope] took a suicidal satisfaction in reminding the reader that the story he was telling was only, after all, a make-believe. He habitually referred to the work in hand (in the course of that work) as a novel, and to himself, as a novelist [...] It is impossible to imagine what a novelist takes himself to be unless he regard himself as an historian and his narrative as a history [...] As a narrator of fictitious events he is nowhere; to insert into his attempt a back-bone of logic, he must relate events that are assumed to be real. ${ }^{\mathrm{I2}}$

Understanding this tendency in Trollope's fiction as something other than 'inartistic', 'inexplicable', or 'suicidal' requires a less pejorative attitude to the novel's artifice. Being conscious of the narrative's imaginariness, as opposed to being tricked (or tricking others) into temporary belief, is not to resign literary value or meaningfulness but to understand the distinctive uses of pretence.

Trollope has good reasons for giving up the assumption of reality in his novels, advantages gained in exchange for puncturing the suspension of disbelief, which form the foundations to his practice of fiction from their origins in childhood play. The explicit fictitiousness of narrative events, their partial freedom from the strictness of causation, allows Trollope the flexibility to plot narrative in ways that a historian could not. Habitually referring to his characters as literary constructs, formed out of conventional tropes, affords a style of psychological characterisation which renders them no less compelling as sympathetic subjects; making up the scenarios by which to practice moral judgement does not preclude their potential ethical value. Explaining Trollope's anomalies as part of a consistent history of practice, from the paracosmic to the literary, enables a sharper 
critical discernment about such uses of the novel distinctively and explicitly 'as a novel', or in other words, as 'make-believe'.

On the most basic level, Trollope is by nature disinclined to conceal the process of invention and compromise that lies behind literary production. As a contemporary reviewer protested in Macmillan's Magazine, Trollope's An Autobiography is uncomfortably explicit about how the sausage is made: 'When an author says that he wrote something for no other reason than to prevent a publisher from going to "another shop" for his wares, we may admit that the literary ideal is brutalized indeed'. ${ }^{13}$ Trollope self-deprecates about his adherence to such banalities, but at the same time, suggests how such practicalities are inseparable from his narrative process. For instance, An Autobiography recounts the inception of Framley Parsonage not from an originating intention or inspiration, but from a series of problems arising out of a contract dispute. As part of Trollope's agreement with The Cornhill Magazine in I859, the publishers Smith and Elder rejected the already in-progress Castle Richmond, as 'an Irish story would not do', and begged to stipulate 'an English tale, on English life, with a clerical flavour. On these orders I went to work [...] [on] an idea of what I meant to write - a morsel of the biography of an English clergyman' ( $A A$ 92). To this half-formed idea of the protagonist Mark Robarts, Trollope added further conditions:

The love of his sister for the young lord was an adjunct necessity, because there must be love in a novel. And then by placing Framley Parsonage near Barchester, I was able to fall back upon my old friends Mrs. Proudie and the archdeacon. Out of these slight elements I fabricated a hodge-podge in which the real plot consisted at last simply of a girl refusing to marry the man she loved till the man's friends agreed to accept her lovingly. Nothing could be less efficient or artistic. (92)

What he articulates through this 'hodge-podge' of contingent needs and materials, in exactly the same voice with which his narrators insist on the necessity of certain contrivances, is an alternative (and really no less 'efficient') writing process than the premeditated composition of a naturalistic narrative. Trollope's novel is designed in response to a miscellany of external and self-imposed requirements - the publishers' 'orders', 'a clerical flavour', an emergency fall-back, 'an adjunct necessity' - which grow to constitute the plot, not as a plan with a coherent rationale, but as a set of personal, professional, and literary problems which instigates the ad hoc solution that is Framley Parsonage.

On another level of deliberateness, this kind of working account is also openly acknowledged within the novels themselves; in a sense, the view 
'behind the scenes' provided by An Autobiography is a redundant one, because a transparent display of the story's mechanics is already on show in the narration. Much as Jameson's admiration for the improvvisatore refuses to separate the finished poem from the 'wonderful exercises' of its production, Carolyn Dever has suggested that the visible artifice of Trollope's novels is an essential component of their appeal; their reading experience does not hinge on suspending predictable outcomes but on 'a full-frontal view of the machinery of plot grinding away for hundreds of pages before this ending is realized'. ${ }^{\mathrm{I}}$ Critics have also registered this spectacle, the novel which shows its working, by redescribing Kincaid's 'formulas' as performances of variation: William A. Cohen argues that a tension between Trollope's progressivism and conservatism is reflected formally in 'the variations [the Palliser series] spins on a relatively narrow set of plot possibilities'; George Levine compares Trollope's works to 'an extended experiment on the human species, not complete until all the variations are played'; L. J. Swingle notes that the marriage plot 'tends to function in a Trollope novel [...] like the "theme" in a musical composition wherein the composer is intent upon developing variations on a theme'. ${ }^{15}$ Each of these critical analogies to political, genealogical, and musical variation, albeit in service to very different arguments, reiterate James's formal observation that Trollope's plots are all 'a love-story constructed on an inveterate system'. ${ }^{16}$ Rather than James's sense of a hidden machine producing derivative art, however, such critics suggest the working process of plot construction as an aesthetic experience in itself, producing pleasure and meaning by way (rather than in spite) of its artifice.

In other words, the bizarreries of Trollope's behaviour in and about the novel is not negligence, but an alternative practice of fiction, aiming at the different artistic methods and possibilities afforded by the novel's 'fabricated' nature. Like Brontë's experiments in Angria, Trollope's work is interested in exhibiting connections between the actual circumstances of authorship and their concrete effects in the imagined world: Framley Parsonage is located near Barchester not because this is simply the geographical fact of the matter, but because Trollope wished to reintroduce several characters from Barchester Towers; Lady Mason will not have a romantic affair, not because her age and station disinclines her to such adventures, but because it is not her given narrative role. Such trains of metaleptic logic are openly advertised in the novel and beyond. As Cohen, Levine, and Swingle point out, understanding the conventions, conditions, or limits within which the narrative operates is vital to a full appreciation of its inventiveness and coherence - much as the spectacle of the 
improvvisatore is incoherent to someone who has missed the challenges and prompts to which the performer is working. Why does the poem alternate between Noah, Caesar, and Pantaloon? Why obey the ridiculous law of the heroine?

To such analogies of variation and performance, the history of Trollope's play practices can offer a fuller and more biographical heuristic for his alternative art of the artificial novel. The possibilities and appeal of an explicitly fictional reality struck Trollope differently than they did Brontë: while for her such worlds afforded experiences of power and wish-fulfilment beyond ordinary limits, Trollope's accounts of his childhood conversely emphasise an interest in imaginary rules and principles, albeit not for some moral objection to imaginative excess (à la Gaskell). What Trollope discovers through play, as equally indulgent as authorial omnipotence, is the experience of flexible invention under conditions (particularly arbitrary ones), long before and anticipating the 'hodge-podge' of professional and generic obligations by which he would later formulate novels.

A literary art of (and a kind of creative addiction to) inventive problemsolving is deeply rooted in the Autobiography's account on the origins of play. Like the story of inventing Framley Parsonage, this account also begins with a series of necessities: in place of a publisher's demand, Trollope started constructing imaginary worlds because 'other boys would not play with me. I was therefore alone, and had to form my plays within myself $(A A 33)$. If the practice is therefore a recourse, chosen because others leave him no choice, he also presents his own psychology as similarly demanding, because 'Play of some kind was necessary to me then, as it has always been. Study was not my bent, and I could not please myself by being all idle' (33). Much of this recurrent framing - he 'had' to, it was 'necessary' - mitigates responsibility for what he apologetically admits to be a 'dangerous habit' (33), but this issue of necessity also continues into his description of imaginative content and process:

For weeks, for months, if I remember rightly, from year to year, I would carry on the same tale, binding myself down to certain laws, to certain proportions, and proprieties, and unities. Nothing impossible was ever introduced, - nor even anything which, from outwards circumstances, would seem to be violently improbable. I myself was of course my own hero. Such is a necessity of castle-building. But I never became a king, or a duke, - much less when my height and personal appearance were fixed could I be an Antinous, or six feet high. I never was a learned man, nor even a philosopher. But I was a very clever person, and beautiful young women used to be fond of me. (33) 
Although Trollope too is interested in wish-fulfilment, its gratifications are remarkably constrained, taking place in-between self-imposed rubrics of 'proportions, and proprieties, and unities'. Even the acknowledgement of wanting to be 'my own hero', the ostensible purpose and pleasure of the fantasy, is expressed and externalised as 'a necessity' alongside other necessities of physical scale, realist probability, and narrative consistency; where Brontë says I want, Trollope says I must want. Just as play apparently originates from a set of needs rather than from any initiative, its contents also seem to be a series of things he cannot help more than he can. Despite the account's association between these two forms of restriction, their analogy has nothing to do with actual necessity - being forced to play alone has no necessary connection to choices about its imaginative scope - and more with how Trollope tends to tell stories through apparent necessity, including the origin story of this narrative method in play.

This history of play offers, for a start, another opportunity to reconsider what has long been taken as Trollope's self-deprecation or inartistry - that he wrote novels out of commercial need, to satisfy requirements, or following conventions - as a more consistent creative principle of 'binding myself down' to problems in order to resolve them with narrative. The language of self-restriction, whether about the discursive conditions of subject matter or the practical circumstances of literary production, recurs obsessively throughout An Autobiography. In addition to the fixed laws of generic conventions and plausibility with which the novelist 'binds himself by the circumstances of the world which he finds around him' ( $A A$ 272), as well as the psychological need or contractual obligations which motivate fiction-making, Trollope also finds it 'expedient to bind myself by certain self-imposed laws' (78) of allotted pages per day, having 'prided myself on completing my work exactly within the proposed dimensions' (79), in these ways 'acknowledging myself to be bound to the rules of labour' (199). As D. A. Miller has argued, the nineteenth-century novel reveals through its 'abundant restrictions and regulations [...] the uneasiness raised in the novel text by its need for controls'; but where he has in mind the discursive forces operating within the text, for Trollope, restrictions of any kind or reason suffice to produce 'the various incitements to narrative' Miller calls the 'narratable'. ${ }^{17}$ Trollope can only seem to write if he is given (or gives himself) no choice but to do so, and moreover, a strict limit on choices about form and content, from adjunct subplots down to the wordcount. If necessities engender invention, such creative conditions can themselves be manufactured, self-binding or self-imposed, like a theme 
that gives rise to variation; rather than limiting his imagination, more rules can only satiate a prolific novelist's gratuitous need for controls.

Play also provides, for another, examples and models for rethinking the novel as an improvised narrative. Beyond the contentions of Trollope's individual reputation as an artist, accounting for his idiosyncratic practices helps us to reposition critical perspective: in general, acknowledging the novel's artifice over its mimetic illusions; and in particular, appreciating the open-endedness of narratives as fictions. Literally and figuratively, Trollope writes by making promises he does not yet know how to keep, whether on the length of a serial instalment, a pre-commitment to 'a clerical flavour' ( $A A$ 92), or some other productive stipulation of his own insistence. His determination of the narrative's requirements in advance, rather than its contents, means that 'with nothing settled in my brain as to the final development of events, with no capability of settling anything [...] I have rushed at the work as a rider rushes at a fence which he does not see' (I I I). Sometimes, he goes on to admit, this has led him to encounter 'what, in hunting language, we call a cropper' (III). At stake in such statements, read less as biographical slapstick and more as aesthetic intention, is a presently undervalued sense of the novel's indeterminacy or incompleteness.

In order more fully to articulate the rules of play which make such incompleteness desirable (and predetermination impossible) in its practice of fiction, I now turn briefly to the De Quincey brothers as a comparative case for Trollope. The open-endedness and arbitrariness of imaginary worlds, qualities which in novel-writing appear as signs of Trollope's unprofessionalism, did not bother these brothers so much as provided energy and opportunity for invention. By placing Trollope's art of conditions within the wider practices of paracosmic play, particularly alongside the adversarial back-and-forth through which the De Quinceys produced their paracosmic narratives, I suggest the pleasures and ethical functions such narratives most have to offer when they least know where they're going.

\section{The Uses of Incompletion}

'It is impossible to imagine what a novelist takes himself to be', James writes, 'unless he regard himself as an historian and his narrative as a history'. ${ }^{8}$ Examining the narratives of paracosmic play makes it possible to imagine exactly this: what a novelist might do by acknowledging their narrative as a make-believe, and conversely, the creative possibilities 
foreclosed by refusing to do so. 'How, and to what extent', a thirteen-yearold William De Quincey demanded of his brother Thomas, 'did [you] raise taxes upon [your] subjects?' ( $A S$ 47). The younger brother rightly sensed a trap behind the question and restrained his 'first impulse to say, that I did not tax them at all [...] because it was too probable he would demand to know how, in that case, I maintained a standing army' (47). Aware of this potential follow-up, as well as of William's belligerence, De Quincey spent 'some days, therefore, to consider the point; but at last replied, that my people, being maritime, supported themselves mainly by a herring fishery, from which I deducted a part of the produce, and afterwards sold it for manure to neighboring nations' (47). This creative answer elaborates on Gombroon's already well-established island geography to deflect William's implicit and implicative threats, but in putting forward a solution that incorporates the existing facts of the game, De Quincey also exposes his people to further indignities that in turn follow or accommodate this new state of play. William 'inferred from this account [...] that the arts must be in a languishing state amongst a people that did not understand the process of salting fish', and moreover 'that a wretched ichthyophagous people must make shocking soldiers, weak as water' compared to Tigrosylvanian troops who - William now asserts - never 'condescended to any thing worse than surloins of beef (47).

This conflict by inventive inferencing only makes sense given an ironic imagination which takes fiction seriously as a factual state of affairs, while simultaneously exploiting the constructedness of fictional facts. Like the Brontëan Genii, the authorial will of the De Quinceys have absolute effect over their sovereign territories. But in order for these children to share a singular, self-coherent, virtual object, to be talking about and acting on the same thing, all 'factual' expressions about the imaginary world must be mutually consented (or conceded) to, kept consistent between them by what De Quincey calls 'the law of the contest between us, as suggested by some instinct of propriety in my own mind':

What [William] said was like a move at chess or draughts, which it was childish to dispute. The move being made [... I I proceeded as a lawyer who moves as long as he can, not by blank denial of facts, (or coming to an issue,) but by demurring, (i.e., admitting the allegations of fact, but otherwise interpreting their construction). It was the understood necessity of the case that I must passively accept my brother's statements so far as regarded their verbal expression; and, if $I$ would extricate my poor islanders from their troubles, it must be by some distinction or evasion lying within this expression, or not blankly contradicting it. ( $A S_{46-47}$, original emphasis) 
In the Autobiographical Sketches, De Quincey retrospectively casts his brother as aggressively asserting, himself passively qualifying, but it is clear from this account that both players accepted each other's 'allegations' as binding conditions, or in attempting to challenge them, did so via new assertions which supplemented their information while subverting their intended purpose. If William seeks to denigrate Gombroon's military power, he must improvise within the possible implications offered by the economic system De Quincey has devised. In the process, he must acknowledge the imaginariness of the facts at hand, because information about actual objects lacks even this limited creative license for elaboration.

Unlike the material world of history, fictional worlds like Gombroon and Tigrosylvania are radically incomplete in their ontology, affording a correspondingly radical view of the relation between narratives and facts. A novel can choose to tell its fictional story as a history, following a naturalistic logic of causes and effects, but in doing so only ignores (rather than refutes) its inherent and partial freedom from the rules of logic as ordinarily applied. For instance, by articulating the 'law of contest' which governs the operation of facts in Gombroon, De Quincey reaffirms the axiom of Aristotelian logic known as the 'law of non-contradiction', which states that 'Nothing can both be and not be'. ${ }^{19}$ That is, a set of contradictory statements cannot both be true. Gombroon may be large, but cannot contain multitudes; if De Quincey claims that it has a herring factory, William cannot also claim in 'blank denial of facts' $(A S 46)$ that it hasn't. But if this law of consistency gives weight to fictional information, allowing subjective allegations to be objectively known, the paracosm strongly violates a complementary axiom in the 'law of the excluded middle', which states that 'Everything must either be or not be'. ${ }^{20}$ That is, statements of fact about the material world must either be true or false. Any historical individual must ultimately be either right-handed or not right-handed, but Anna Karenina can be neither by virtue of her under-determination as an imagined entity. Even if Tolstoy's novel were to determine this aspect of its world, the most maximalist of narratives still cannot match the infinitely propertied nature of any material object; Karenina would still have an indeterminate shoe size, number of eyelashes, and so on, facts which are all fundamentally true or false (even when unknown) about an actual person.

Narratologists and philosophers have long debated the extent to which such gaps are filled in or left out during the reading process, especially for the novel as a genre which demands and assumes significant contextual knowledge about contemporary settings. ${ }^{2 \mathrm{I}}$ As Lewis argues in his seminal essay 'Truth in Fiction', it is safe to assume that certain facts in the fictional 
world created by Arthur Conan Doyle possess truth or falsity even when not directly referenced in the narrative; for instance, that the greater geography of Victorian London more-or-less exists beyond Baker Street and the settings of the adventures; or that the Second Anglo-Afghan War, where Watson is injured before the adventures, played out in a similar way to how it did historically. ${ }^{22}$ But 'Is the world of Sherlock Holmes a world where Holmes has an even or an odd number of hairs on his head at the moment when he first meets Watson? What is Inspector Lestrade's blood type? It is absurd to suppose that these questions about the world of Sherlock Holmes have answers'. ${ }^{23}$ For the De Quinceys, however, this ontological peculiarity matters less as a theoretical problem as for its practical implications to their fictional enterprise; already inhabiting the rules of a complex ontology by 'instinct', they are conscious of the inherent gaps in fiction as potential vulnerabilities or escape routes, where a fatal or redeeming qualifier might suddenly redefine the status quo.

For the De Quinceys - and for understanding the uses of fictionality incompleteness is not a philosophical problem but an available space of play, the kind of productive insufficiency that provides further 'incitements to narrative'. ${ }^{24}$ The state of Gombroon's taxation was not only indeterminate for the brothers but undecided, a still-malleable aspect of the world on which De Quincey can exercise creative invention, but which would in turn produce fresh possibilities at the new borders of 'verbal expression'. The availability of a constant indeterminacy is a feature of fictional worlds which enables paracosmic play to sustain narrative indefinitely, and represents an essential component of its wider practice: these children recurrently represent narrative progression or change as an encounter between new assertions and the facts as previously established, whether with siblings or by themselves. Jameson, for example, describes each new 'series of actions, scenes, and adventures' that arise in her private world as 'one springing out of another, and coloured and modified by increasing knowledge'; ${ }^{5}$ while Derwent Coleridge describes Hartley as 'evolving the complicated drama of existence [...] [through] changes of government, a great progress of public opinion and a new order of things!' ( $H C$ xliii-xliv, emphasis added). Afforded by the nature of the paracosm as a virtual object, these accounts emphasise the act of fiction-making as outgrowing from an always mutable and never completed present, creating new excitement and stories out of accumulatively rearranging the fictional state of affairs.

Here again, the paracosm helps to upend our view of the novel by embodying, to extravagance, aspects of its fictionality more usually 
considered peripheral or ambivalent to the central values of the form. '[W] hat discontents the traditional novel', Miller argues, 'is its own condition of possibility. For the production of narrative [...] is possible only with a logic of insufficiency, disequilibrium, and deferral, and traditional novelists typically desire worlds of greater stability and wholeness than such a logic can intrinsically provide'. ${ }^{26}$ But what requires recognition, too, is a tradition of fiction which enshrines the 'condition of possibility' as its primary appeal and form of sense-making, preferring worlds of inherent incompleteness over those of stability or wholeness. In the following chapter on sequels and continuations, I return to the problem of closure by examining how authors such as Thackeray were indeed seriously discontented with the need for novels to end. For the moment, however, such a problem does not come up for Jameson, Coleridge, or the De Quinceys, who have markedly different motivations for fiction-making than 'traditional novelists'. Nor for Trollope, who discovered in the imaginary world a hyperbolic source of narratability, insufficiency enough to 'carry on the same tale' for years and years, explicitly questioning 'whether, had it not been my practice, I should ever have written a novel. I learned in this way to maintain an interest in a fictitious story' ( $A A 33)$. Recalling the scene of Eleanor's convenient lack of tears - 'where would have been my novel?' (BT 24I) - the indispensable condition of the novel for Trollope is its capacity to avoid a final determination of facts - 'Everything would have been explained' (24I) - at least for now, if not forever.

The fun and meaningfulness of paracosmic narratives are to be found in the artificial logic of their invention, affording a continually creative relation to unexpected conditions. Such narratives are not only unplanned and unending, but inherently unplannable and open-ended, arising out of an indefinite process of elaboration whose destination can never be fully pinned down, or even more chaotically, from a back-and-forth between multiple authors who regularly contort the shared story in perverse directions. As Trollope always claimed, the Chronicles of Barsetshire was an unplanned enterprise; nonetheless, accumulating new families, townships, and narratives for his fictional county over a six-novel series, 'to go back to it and write about it again and again has been one of the delights of my life. ${ }^{27}$ Such revisitations not only take the narrative further along in time, but reveal Barsetshire as a world about which there is always more to say than any novel has the capacity to conclude. This is a view of the novel that, as I have argued, acknowledges its nature as a fiction; as we will see, it might also be a view of the world, a kind of moral optimism that people and situations are never beyond redemption. 


\section{'Protestations of Unpreparedness'}

'[O] ur admiration of The Last Chronicle [of Barset] would be even greater if we were able to disregard what Trollope says', argues the critic Anthony Arthur. ${ }^{28}$ Like James, Kincaid, and the reviewer for Macmillan's, Arthur echoes a sentiment of Trollope as his own worst enemy, a committer of serial artistic suicide, which I have argued to be a misrecognition of Trollope's actual narrative values. Arthur's specific example - the life and death of Mrs Proudie - is a good final case for re-evaluating 'what Trollope says', and how we might differently admire his work. Like Lady Mason, Mrs Proudie's introduction and characterisation in Barchester Towers is an act of ostensible compliance with a novelistic law:

It is ordained that all novels should have a male and a female angel and a male and a female devil. If it be considered that this rule is obeyed in these pages, the latter character must be supposed to have fallen to the lot of Mrs. Proudie. But she was not all devil. There was a heart inside that stiff-ribbed bodice, though not, perhaps, of large dimensions, and certainly not easily accessible. ( $B T$ 204)

If one possible implication of this passage is a realist ethical principle about the irreducibility of persons to type, what it explicitly argues instead is that Mrs Proudie is the way she is due to her nature as a fictional character, contingent to but incompletely defined by conventions. She is revealed as having a heart not because even devilish people have hearts, but because (radically unlike any actual person) the facts of her nature and history as a fictional character are available to be continually qualified in this way. As Sophie Ratcliffe has argued, Trollope's sense that individuals can be 'dual in character' is connected to a working process where the novelist allows himself 'to be inconsistent, to revise his opinion, and to edit [...] Trollope's writing methods enable such duality'. ${ }^{29}$ The stark rhetorical turn of this passage, in which the passive voice of obligation ('It is ordained', 'If it be considered', '[it] must be supposed') gives way to positive declarations ('But she was', 'There was'), models this relation between the conditions of novel-writing and the qualities of a fictional personality: the narrator first establishes her necessity in the stock role of the villain, then opens a certain latitude or variability within that 'stiffribbed' form. Mrs Proudie owes her complex moral psychology, the narrator tells us, to the available caveats (rather than restrictive determinism) of the novel's 'romantic comedy formulas'. ${ }^{30}$

As narrative plot, Mrs Proudie's nature as a fiction also governs the circumstances of her demise. Although, as Arthur notes, contemporary 
reviewers did not seem to register Mrs Proudie's death in The Last Chronicle as an unusual development, An Autobiography later revealed its unusual causes behind the scenes of narrative. At work on The Last Chronicle in the Athenæum, Trollope overheard 'two clergyman [...] abuse what they were reading, and each was reading some part of some novel of mine':

Then one of them fell foul of Mrs. Proudie. It was impossible for me not to hear their words, and almost impossible to hear them and be quiet. I got up, and standing between them, I acknowledged myself to be the culprit. 'As to Mrs. Proudie,' I said, 'I will go home and kill her before the week is over.' And so I did. The two gentlemen were utterly confounded, and one of them begged me to forget his frivolous observations. ( $A A$ I 72$)$

This episode is a striking account of Trollope's working process, spinning narrative ad hoc out of unnecessary, arbitrary, and extradiegetic conditions: 'It was impossible for me not to hear [... ] I could not, I think, have done it, but for a resolution taken and declared under circumstances of great momentary pressure' ( $\mathrm{I} 72$ ). If the decision is spontaneous and 'momentary', responding to a 'frivolous' and accidental situation, it is also a binding 'resolution' about a character who has spanned ten years and five novels of work. The account is temporally disrupted by this contrast between timescales, jumping proleptically from Trollope's conversation in the club to later in the week - 'And so I did' - and then back again to the clergyman asking, evidently in vain, to undo the damage. Within the novel itself, Mrs Proudie's body undergoes an impossibly accelerated rigor mortis that keeps it 'still resting on its legs, leaning against the end of the side of the bed, while one of the arms was close clasped round the bedpost' ( $L C B$ 594), as if the immediacy of authorial decision has flash-frozen her in the fictional world, and her sudden passing is attributed to that small, hidden part of her construction: 'It's her heart [...] though nobody knew it. She was very shy of talking about herself (594).

The sudden claim that Mrs Proudie has always had a 'heart complaint' ( $L C B$ 594) - or rather, that she was never declared as not having one exemplifies that space for 'distinction or evasion' ( $A S$ 47) intrinsic to all fictional information. The rumours of Mrs Proudie's heart play this function twice over the novel series, revealing within the established facts of Barsetshire the possibilities for surprising qualifications not yet determined or contradicted by narration; this is reinforced by the suggestion that her condition had been hidden because of a particular shyness, another retroactive quality to the unrepresented private life of an 
outspoken character. These eulogistic footnotes work against Arthur's argument that the scene represents a symbolic climax to Mrs Proudie's personal inflexibility, and a premeditated end to her character, that she 'die[d] as she had lived: rigid, unyielding, incapable even physically of registering defeat'. ${ }^{3 \mathrm{I}}$ Where this reading emphasises the inevitability of Trollope's 'calculated dispatch, not only justifiable but necessary in terms of plot and characterisation', the novel itself balances the finality of her death with the abruptness of the event, the impossible stiffness of her body with revelations of an unsuspected softness. ${ }^{32}$ There is a certain rigidity itself to Arthur's insistence against the spontaneity of this episode, his search for justifications from the preceding narrative and novels, which overlooks the real 'appropriateness of the death in the series' as an accumulation, rather than a culmination. New surprising claims about an old familiar character exemplify how the Barsetshire novels have always followed each other: not as a systematic survey of a predetermined county, but the filling-in of gaps between known locations, and the steady addition of local families over time who have suddenly always been connected to characters of previous novels. ${ }^{33}$ Even without Trollope's account in $A n$ Autobiography, Mrs Proudie is clearly killed in this spirit of the paracosmic ad hoc, a 'great momentary pressure' ( $A A$ I 72$)$ rearranging the lines of long-established fictions.

Arthur's discomfort with authorial spontaneity not only belies the wider critical ambivalence towards Trollope's accounts of himself as an artist, but a critical method at a loss for interpreting the novel as fiction - the arbitrary and incomplete, the possible rather than the inevitable, affording opportunity rather than closure. What Sedgwick has characterised as the 'anticipatory' tendency of criticism or its 'aversion to surprise' manifests here as a criteria applied to an author who systematically disclaims foreknowledge for spontaneity, and whose example suggests the forms of knowledge afforded by less knowingness. ${ }^{34}$ In An Autobiography, Trollope repeatedly asserts that 'the incidents of the story [...] were created for the most part as they were described. I could never arrange a set of events before me' ( $A A$ 197), or with more specific reflection in his essay 'A Walk in the Wood':

[T]o construct a plot so as to know, before the story is begun, how it is to end, has always been to me a labour of Hercules beyond my reach. I have to confess my incidents are fabricated to fit my story as it goes on [... I I wrote a novel once [Orley Farm] in which a lady forged a will; but I had not myself decided that she had forged it till the chapter before that it in which she confesses her guilt. In another [The Eustace Diamonds] a lady is made to 
steal her own diamonds [...] but the brilliant idea only struck me when I was writing the page in which the theft is described. (266)

The volume and explicitness of such statements make them hard to 'disregard', even harder to separate from the narrative events they specify; defending the novelist from himself, Arthur argues that 'Trollope consistently understates throughout his Autobiography his commitment to a higher concept of his art than such an arbitrary action could accommodate'. ${ }^{35}$ John Sutherland similarly argues that we 'should be sceptical of the novelist's own protestations of unpreparedness [...] Trollope's selfdeprecating description of himself as charging at the plot'. ${ }^{36}$ Such resistances, not only to the author's accounts of his work, but also to how the novels account for themselves, represent an evaluative and interpretive position from the standards of a Jamesian formalism to which Trollope is explicitly not signed up, and to which his many statements of artifice and invention necessarily register as irrational or self-critical. ${ }^{37}$ But it is exactly in 'their queer elements of the accidental and the arbitrary' where Trollope's novels, like the narratives of play, locate the distinctive value of fictions as fictions - and where we must search for new critical standards. ${ }^{38}$

What kind of interpretive judgement do the Barsetshire novels allow of Mrs Proudie? Not one that is applicable to any historical individual, but at the same time, nor one therefore devoid of meaning. If, in the peculiar causation of novel-writing, Trollope has 'fabricated' a heart condition and justified it after the fact, it is not uncommon in actual life that the bereaved make unexpected discoveries about the deceased, aspects of their lives or personalities which have been true all along but unknown. This is not a mimetic or historical relation - what happened to Mrs Proudie could not literally happen in real life - but an analogy for our incomplete knowledge of people and the world around us. The difference, of course, is that what Trollope does not know about Barsetshire represents a creative opportunity, whereas our ignorance about the full facts of our world does not negate their objective truth and effects.

But are there advantages to thinking creatively about actual situations, especially about ethical dilemmas, in the way Trollope views narrative plot? David Russell has argued for what he calls a 'virtual sensibility' in the essays of Charles Lamb, whose anecdotal narratives recurrently depict 'an attitude of disinterest, of not wanting to know the facts, that provides the conditions for the pleasurable surprises of new experience' ${ }^{39}$ If this is an analogue for how Trollope generates narrative, it is also for Lamb a model of behaviour: a 'social relation of benign unknowing'. ${ }^{\circ}$ Encountering a 
beggar in the city who is either feigning or not feigning their distress, Russell points out how 'the notion that he could know the truth of the other is quite inappropriate to the situation [...] Lamb refuses to decide whether the beggar really is in as much trouble as he says'. ${ }^{4 \mathrm{I}}$ Embracing an incomplete view of the world might be more ethically valuable than a deterministic view that the facts are out there (even though they are); in other words, Lamb approaches the situation as if it were fictional, imagining that the beggar is neither lying nor not lying except as you are free to entertain it.

The following reading of The Small House at Allington proposes the ethical value in a fictional view of the world. Trollope's characters in this novel qualify and demur; they contemplate the binding force of their principles or commitments; they believe (generally correctly) that their personal dilemmas have some hope of future exemption or change. Critics since Ruth apRoberts have characterised their mode of moral dissembling as casuistry or situation ethics, a process of considering the full specificities of the case rather than applying categorical imperatives, waiting to review more of the circumstances before giving any verdict. ${ }^{42}$ But how does one practice 'situation ethics' on situations which are imaginary, particularly as imagined by a novelist who has not completely decided the facts of that situation when he began to write it? Acknowledging the inherently artificial logic of the novel turns the process of casuistry on its head: instead of coming to a conclusion about pre-existing particulars, moral reasoning in an incomplete world constitutes inventing the right rationale or qualification that will retroactively become the solution. Trollope's characters behave as if they are aware of this, and are plotting alongside their author to get out of (or get away with) the narrative conflict. This is an admittedly troubling view, potentially reducing ethical deliberation to arbitrary rhetorical puzzles like that over Gombroon's taxation. But just as for De Quincey, it might also be a hopeful view: always reserving the possibility that things might be better than you know. 


\section{THE SMALL HOUSE AT ALLINGTON}

Although much has been said about the notion of Trollope's casuistry, either as a proposed model for his beliefs or on its validity as a philosophy in general, less attention has been given to the art of its narrative pleasures. In her classic study Artist and Moralist, apRoberts identified Trollope's casuistry as 'a more flexible morality' in which behaviour and judgement require 'the most careful, detailed consideration of the circumstances, even of a "crime", rather than the reductive application of 'some theory, some precept, some generalisation [...] any precept or theory can be invalidated, by some case'. ${ }^{43}$ Holding off premature judgement for a period of purposeful indecision, an attitude of 'benign unknowing', the depiction of this process in prose is one apRoberts finds not only ennobling (on which her critics tend to disagree) but also pleasurable: ${ }^{44}$

The art of [casuistry] makes us see the uniqueness of character in circumstances, and the end of it is moral perception. It is a very satisfactory thing that the means to this end is so delightful that we can take the means for an end, and the end still achieves itself. [...] [Likewise,] One of the incidental pleasures of the novels is Trollope's positively virtuoso display of a variety of lawyers in action. ${ }^{45}$

ApRoberts comes close here to implying that, even if casuistry were not the effective philosophy she argues it to be, it could still have value as an aesthetic experience, like a 'virtuoso display of [...] lawyers in action' whatever they may be advocating. It is with such pleasures of performing deliberation that a typical Trollope narrative 'catches us [...] with a case in which the moral ambivalence is striking [...] carefully selected and significant cases constitute his content'. ${ }^{46}$ Andrew H. Miller picks up her argument on this point, noting the narrative appeal of casuistry to the realist novel as a genre 'devoted to the display of consciousness'; by drawing attention to the processes of thought and perception, 'casuistry is a performance, for the casuist himself or herself first of all. We are receptive audiences for our own ethical dramas'. ${ }^{47}$ We are evidently receptive, also, to the novel's performance of explanation about its own made-up situations, perhaps even preferring the virtuosity afforded by complex or ambiguous dilemmas - otherwise where would be the novel? over clear-cut cases of right and wrong.

The clear danger in this aestheticisation of moral reasoning, in finding the performance of casuistry 'delightful' in itself, is that we might come to confuse narrative proficiency for moral clarity. This is the objection most 
commonly associated with the term 'casuistry', already widely recognised in the nineteenth century, as 'a quibbling or evasive way of dealing with difficult cases of duty; sophistry. ${ }^{48}$ As Kincaid argues in rebuttal to apRoberts, for all that Trollope admires a lawyer's consideration of the facts from every angle, he just as often portrays the speciousness of neutrality, such as in his unflattering portrait of the politician in The Eustace Diamonds: 'a large-minded man of the world, peculiarly conversant with the fact that every question has two sides, and that as much may often be said on one side as on the other [...] [who] sees there is an opening here or an opening there' ${ }^{49}$ Miller raises the similar case of Ferdinand Lopez in The Prime Minister, introduced in the novel as 'an accomplished linguist, and as a very clever fellow', who employs his rhetorical talents in the service of 'talking himself into pocketing money [...] reflecting and inclining and questioning and resolving, a process of casuistical ingenuity. ${ }^{50}$ In such examples of what Miller terms 'casuistry downward, as it were, ingenuity in the service of self-deception', more commonly represented in the nineteenth-century novel than 'where such deliberative reasoning is approved by the writer [...] as casuistry upward', the virtuosity which sustains narrative pleasure also convolutes moral judgement. ${ }^{5 \mathrm{I}}$ If casuists insist on keeping open a 'condition of possibility' in moral judgement, how do we reach a final moral conclusion? How do we avoid leaving room for further, potentially specious claims of leniency or exception, 'an opening here or an opening there'?

On the level of composition, I have proposed a deliberate artistry in the contrivance and artifice of Trollope's narratives; here, I reclaim the specious, the spurious, and the sophistic as morally useful qualities in his fiction. It is not so bad in Barsetshire to be clever about being good; while Trollope undeniably condemns self-deception and excuse-making in his villains, he also appreciates the fastness and looseness with which virtuous characters play difficult moral choices. These positive representations of evasiveness occur partly because apRoberts is right to identify Trollope's attraction to moral wriggle-rooms. It is also partly because fictional worlds operate on different rules to ours, including those of moral causation and explanation. If in life, casuistry can destabilise or manipulate the true facts or logic of the case, in fiction (especially in the unpremeditated plots of Trollope's novels), facts and logic are inherently unstable, constituted only by their consistent 'verbal expression' and reshapable as truths by creative reasoning. If casuistry assumes no moral precept can encompass the full complexity of possible situations, this is axiomatic to a world of radical incompleteness, where no determination can fully render a situation 
beyond qualification. The moral logic of Trollope's fiction, much like its narrative logic, is open to ingenious elaborations which would be disingenuous in life or history.

In this reading of The Small House at Allington, I examine Trollope's qualified support for a fictional or creative morality, by comparing two characters who allow themselves to perform actions they knew or thought to be wrong, but which they come after further reasoning to consider permissible, even morally desirable. Because the novel presents Mrs Dale and Adolphus Crosbie as morally poles apart - one arriving honestly at a just exemption, the other excusing himself into villainy - their strikingly similar processes of thought form a kind of meta-casuistry. What I propose separates narrative endorsement in the one case from condemnation in the other is not a difference of extenuating circumstance (as the non-fictional practice of casuistry would seek to reveal), but a difference only in skill and success. The logic of moral explanations in the novel is inextricable from the way Trollope's novels work themselves out as they go along - the mechanisms upon which their fictional realities operate - either successfully justifying the facts after the fact, or losing rhetorical control of the situation. Although she does not think of herself as such, Mrs Dale is simply a better improviser, selfadvocate, or tactical player than Crosbie, contriving a more plausible story of justification than his collapsing account of inconsistent commitments.

Sophistry is an artificial logic, a view that moral reasons (like novels) are all made up, but it is not necessarily a moral nihilism. As this book argues, novel fictions possess different kinds of values and functions by virtue of its artifice than of mimetic representation. As historical individuals, we do not live in an incomplete world with indeterminate chains of causation, but by imagining that we do, we might see that our circumstances are often less determined than we think, and our moral options more flexible. The experience of Trollope's fictional world cultivates, if not exactly casuistry as apRoberts describes it, is nonetheless a 'more flexible morality' in which rightness is constituted not by the strictness of rules, but by the ability to account for one's actions within them - by morally getting away with it. ${ }^{52}$ Through their artistry, Trollope's novels exhibit such ingenuity as a compositional process; through their characters, they propose its contentious value as a creative way to live.

\section{The Case of Mrs Dale's Reneging}

Rather than a casuistic flexibility, critical studies of The Small House have tended to emphasise an opposing theme of moral resolution or 
stubbornness - focussing particularly, but not exclusively, on the refusal of its heroine to marry another suitor after being jilted by her original choice. Matthew Sussman, for example, characterises Lily's continued love for Crosbie as 'an ideé fixe that she seems unable or unwilling to shake [...] an attachment that strikes her family as self-destructive and perverse'. ${ }^{53}$ Dinah Birch similarly argues 'that the success of The Small House at Allington depended on the steadfastness of Lily Dale', and moreover that 'Lily's intransigence [...] forms part of a pattern that repeats itself throughout the novel', both within her family and among other characters. ${ }^{54}$ Taking the novel as exemplary of Trollope's work more generally, Amanda Anderson has noted the distinctiveness of his 'recalcitrant psychologies', a state of individuals being 'obsessively dedicated to, or trapped by, their own psychological postures, which in themselves often express an excessive or unreflective relation to a position or principle that cannot be relinquished'. ${ }^{55}$ Even a case where a character seems clearly to change her mind - Lily's sister Bell initially refuses, than accepts the proposal of Dr Crofts - is placed in the context of Bell's principled rejection of her other suitor, and in any case 'is not a genuine exception to the novel's dominant pattern of behaviour, for [...] Bell has committed herself to Dr Crofts from the very first, without fully understanding her own feelings' ( $\mathrm{SH}$ xiv).

This critical emphasis on the fixity of Trollope's characterisation is fundamental to an interpretation of his narratives as hinged upon an a priori and diegetic logic of character. This formulation has been most strongly articulated by Stephen Wall, who has argued for the 'freedom [of Trollope's characters] to follow the emerging logic of his or her own nature', such that 'the circumstances being what they are and the protagonists being as they are', the novel's narrative follows naturalistically from 'the logical and psychological effect produced by the combination'. ${ }^{56}$ In this model of the autonomic, emergent, or character-driven novel, the coherency of plot might therefore depend upon a style of characterisation which disproportionately favours the obsessive, the intransigent, and the recalcitrant, upon characters who act in accordance with a visible logic. This is particularly true of The Small House, which as Sussman has argued, is 'the first of Trollope's novels in which the plot is fully motivated by psychological characterisation', and also one thematically concerned with constancy. ${ }^{57}$ In this argument, characters can surprise us, but only in ways that make 'sense' with what we already know of them - ideally, like Lily Dale, they do so with extraordinary perseverance in their existing positions - because characters whose rationales are inconsistent or obscure would threaten the meaningfulness of Trollope's narrative. 
I want to offer a counterpoint to this model, an argument for greater indeterminacy in the novel's narrative and moral logic, through the example of a subplot whose motion cannot described as anything other than a prolonged backpedal. In a sequence of events that come to relatively little consequence, and occur in-between (sometimes literally sandwiched within passages about) the Dale sisters' respective, dramatic marriage plots, Mrs Dale decides to, and then decides not to, vacate the building of the novel's title: the Small House at Allington, which she and her daughters occupy by long-standing family arrangement with the squire of the Great House, Christopher Dale. This accommodation sours midway through the novel, not from misunderstanding or accident but because, as Hillis Miller puts it, 'Trollope's characters play their roles to the hilt'. ${ }^{58}$ Because Bell rejects the squire's plans for her marriage and resents his presumption to make them for her, the Dale women feel increasingly uncomfortable about living off his patronage while refusing his paternalism: Bell reflects that in accepting his kindness, we ought to submit ourselves to him. If that be so, it is a conclusive reason for our going [...] it would be impossible to remain here' ( $\mathrm{SH}$ 337); Mrs Dale similarly feels 'she now had no alternative. She could not now teach her daughters to obey their uncle's wishes [...] She had gone so far that she could not go back' (339). The decision is repeatedly framed as inevitable - the consequence of things and people being as they are - in addition to being charged with moral purpose, involving a sacrifice in social and living standards because they could not 'purchase those luxuries which they were about to abandon at the price which was asked for them' (340).

So it strikes the Dales themselves as somewhat ridiculous when, nineteen chapters later, their decision is categorically unmade. 'What geese everybody will think us!' (SH 5I3) Lily jokes, 'We shall look such fools!' (52I). By this point, news of their move has passed from rumour to public knowledge, alternative lodgings have been acquired, and in a chapter entitled 'Preparations for Going', they have taken apart their home: 'they began it much sooner than was necessary, so that it became evident [...] that they would have to pass a dreadfully dull, stupid, uncomfortable week at last, among their boxes and cases, in all the confusion of dismantled furniture' (442). This uncomfortable period suggests both a pre-emptive over-commitment (they packed too early) and, at the same time, a symbolic suspension of fixed positions: Bell's engagement is comically settled with Dr Crofts 'seated in the middle of the room on an empty box', and her 'upon the lump of carpeting' (452). It is during this paradoxical combination of domestic arrangement and 
disassembly, the committed and the provisional, that Mrs Dale begins to invert her position: 'It was too late to abandon her project of moving and remain at the Small House, but she almost confessed to herself that she repented of what she was doing' (450). If this is consistent with her original regrets about the plan's circumstantial necessity, she now considers it in less circumstantial terms:

'Do you mean you repent?'

Mrs Dale did not answer her daughter at once, fearing to commit herself by words which could not be retracted. 'Yes, Lily; I think I do repent. I think that it has not been well done'.

'Then let it be undone', said Lily. (48I)

Mrs Dale's repentance matters less here than how the situation's inevitability has been reframed from that of leaving the Small House to remaining in it. Rather than the move having 'gone so far that she could not go back' ( $A S$ 339), it is now the decision to stay 'which could not be retracted' (48I); where it was first 'settled among them [...] to quit the Small House' (338), it has now come 'to be the fixed idea [...] that they would abandon their plan of migrating' ( $5 \mathrm{I}_{3}$, emphasis added). The reversal of this subplot is not framed as their relenting, but the overtaking of one strong resolution by another; superficially vindicating the novel's reputation for fixity while in fact unfixing the motives of character. The aggregate pressure of personal resolve which made action so necessary in the first place becomes redeployed to present the opposite course of action as equally necessary: remaining in the Small House, paradoxically like leaving it, is suggested as the only psychologically and morally consistent option.

'The Fate of the Small House', as one chapter title terms it, forces us to reorient our understanding of the novel's fictional causation. Rather than the critical commonplace that Trollope's characters drive the narrative through adhering to 'an ideé fixe', characters in fact act by leaving themselves no choice, binding themselves down in order to exercise their agency, in a reflection of the compositional process by which the novel itself is plotted. While Mrs Dale is clearly changeable on the level of her 'idea', and not so apparently deadlocked by 'impossible' circumstances which allow of 'no alternative' (339), she remains attached in her thinking to an aesthetics or rhetoric of the 'fixed idea', fixated with projects 'too late to abandon' (450) or words 'which could not be retracted' (48I), even as these refer to diametrically opposed courses of action. To take another example in a more obviously compromised character, Joseph Cradell 
explains his engagement to the beguiling Amelia Roper as having 'now gone too far for any alteration [...] nor would any mere earthly inducement suffice to change me' (529). The order in which he presents these two justifications strikes his friend Johnny Eames with grim amusement, and exemplifies the Sartrean bad faith with which Trollope's characters appear to follow their resolves: individuals who claim to be bound by their own decisions put these claims ahead of their capacities to decide. ${ }^{59}$ Dissimilar in almost every other respect, Mrs Dale shares with Cradell this tendency to frame choices through (self-imposed) obligations: having reconciled with the squire, she announces to Lily that "We may certainly unpack, for I have pledged myself to him' (52I) to stay.

Trollope's characters do not have strong convictions, but rhetorical positions which they enforce in an illusion of moral will. They in fact distinctively lack conviction, because they behave almost entirely through making public commitments, never asserting their desires or preferences so much as protesting the apparently inevitable logic of his or her own nature. ${ }^{60}$ This mode of thought and behaviour is exemplified not only by the novel's subplots, but also by its central dilemma: compromised in a different way to Cradell, Lily rejects the possibility of a second engagement to Johnny because 'I should be disgraced in my own eyes if I admitted the love of another man, after - after -. It is to me almost as though I had married him' ( $\mathrm{SH}_{489}$ ). Framing her decision not as a decision but as a corollary of her previous commitment, her rejection also strikes others as producing an impasse: Johnny thinks it 'impossible that he should continue his suit after such a declaration' and Mrs Dale that 'words have been forced from Lily's lips, the speaking of which would never be forgotten by [Lily] herself (489). All the while that the focus remains on this tactical deadlock, what exactly Lily continues to love about Crosbie is given short thrift, and her exact feelings on Johnny curiously elided as irrelevant or indeterminate. More than an obsessive constancy to a particular object, or even constancy as a virtue in the abstract, Lily is possessed by the facts of her previous admissions, 'declaration', and 'words'; that is, by the language through which she is in fact constructed as a fictional character. Anderson is right to describe this situation as that of an individual being 'trapped by [...] their own psychological postures', and Wall as Lily being 'caught in a trap of her own making, or which at least she could not stop herself making', but this metaphor of an autonomous thing constrained in a sense reverses the case: Mrs Dale, Cradell, and Lily are made of their constraints. ${ }^{6 \mathrm{I}}$ Their characterisation is the shape outlined by the trap. 
They behave, in other words, like Mrs Proudie's heart condition: neither true nor false until its consequences become known. If, in the diegetic chain of causation, Lily's decision reveals the underlying logic that has determined that result from the start - as apRoberts puts it, Trollope 'will not let Lily Dale marry Johnny Eames because she wouldn't have' from an extradiegetic perspective of the narrative as a progressive accumulation of fictional statements, her decision newly determines (partly through an interpretation of previous narrative facts) what that logic has been all along. ${ }^{62}$ Trollope's own view, as James lamented, is a metaleptic straddling of the two in which the possible undoing of Lily's dilemma is a question of psychological artifice: now that she has said this, is there any way she can accept Johnny without contradicting herself? Is there a plausible account of her character or situation which could reconcile these positions? That Lily's engagement to Johnny persists so long as an optative possibility through the plots of two novels (The Small House and The Last Chronicle) speaks to a sense in which, as the De Quinceys knew, fictional facts are unlike real facts in that they are constituted by their 'verbal expression', and therefore infinitely vulnerable to reinterpretation or erratum which might at some point undo the force of the dilemma.

Undermining the internal reality or completeness of characters in this way, denying a predetermined or essential coherence from which external actions originate, would seem to realise the worst fears of casuistry's critics: the dissolution of principled into arbitrary action through post hoc justifications. By entertaining 'whether a particular act fits within an ethical paradigm and allow[ing] each - act and paradigm - to modify the other', we might arrive at a state of made-to-fit moral duties which can always be rendered less binding. ${ }^{63}$ As Ratcliffe has pointed out, Trollope's respect for the personhood of characters is balanced by a sense of their subjection to the writing process: when he discovers that 'some young lady at the end of a story cannot be made to be quite perfect in her conduct, that vivid description of angelic purity with which you laid the first lines of her portrait should be slightly toned down' $(A A 90){ }^{64}$ This seems not only to constitute a qualification of character - as with the hidden heart of the female devil - but also a compromise of moral ideals, adjusting the standards of the angel to accommodate behaviour after the fact. Along these downward toning 'lines', Mrs Dale's original ultimatum between the sacrifice of luxury or principle is finally not to be decided, but adjusted in terms of its question so as to allow for no sacrifice after all; the novel succeeds at evading its own moral challenge. 
The task of interpretation in such instances is, for one, not to give up the matter as fictional and arbitrary (all novels are fictional and arbitrary), but to appreciate the skill with which Trollope talks the plot out of its own premises - to acknowledge his specious art of narrative. As I have argued, opening 'not easily accessible' (BT 204) gaps in established states of affairs is characteristic of Trollope's narrative process. As Helena Michie has also pointed out, on the level of style, Trollope's prose is characterised by an "internal revision", a process by which he uses one sentence to revise another, leaving the original sentence on the page [...] differences between sentences in Trollope [are] accretive - that is, slowly adding up over time'. ${ }^{65}$ If the author's tendency in narrative problem-solving is 'to work the matter out when the pen is in my hand' ( $A A$ I 45), his characters also perform their moral reasoning live, as it were, thinking about what they have already committed to the page, in a necessary parallel between the extradiegetic dynamics of writing and its representation of 'the process of thinking [...] the complicated and recursive logics through which people are said to "change their minds"' ${ }^{66}$

For another, more difficult task, critical approaches must also evaluate how fiction's inherent open-endedness structures its moral perspective, and what ethical value the novel assigns to the kinds of flexible thinking it most readily represents. The Small House unambiguously endorses, has little more to even say about, Mrs Dale's rearrangement of the conditions by which her present course once appeared 'impossible'. Whether or not the subplot's self-deflation indicates one of those instances where incidents have been 'fabricated to fit my story as it goes on' ( $A A$ 266), the narrator and other characters clearly sanction Mrs Dale's reconsidering of circumstance. This is not always Trollope's judgement on such cases. The example of Mrs Dale bears comparison with others where characters are soundly reprimanded in and by the narrative for trying to adjust their commitments, particularly in the higher stakes of the engagement plot. Yet because the maligned vacillation of Trollope's jilts are - as I will show formally indistinguishable from Mrs Dale's, I argue that what such examples recommend is more creative morals, not less; better revisions, rather than stronger resolutions.

\section{The Case of Adolphus Crosbie's Jilting}

The Small House and its immediate successor, Can You Forgive Her?, can be read together as a diptych of novels about engagements. Although both novels ostensibly present their heroines with a choice between two 
partners, this traditional question of the marriage plot is subordinated to the less binary problem of engagement, concerned with possibilities for agency given a seemingly foregone conclusion. Lily is engaged by chapter five of sixty, and Alice Vavasor from the novel's outset, but this is not all there is to say about their situations. As Sussman has argued, Trollope discovered a rich vein of narrative potential in the 'complex middle ground' between singlehood and marriage, 'where the technical commitment remains provisional but the moral barrier to exit is high' ${ }^{67}$ We have already seen this dynamic, even metaphorical language, at work in subplots which do not literally concern engagements: 'I have pledged myself to him', Mrs Dale says of the squire, after reneging on a move she once thought to be irreversible, 'and he is to go into Guestwick himself and arrange about [i.e., to cancel] the lodgings' (SH 52 I, emphasis added). In form rather than as subject, engagements exemplify a category of social facts especially conducive to fictional narrative: which are neither truth nor falsity but an amenable 'verbal expression', a claim which is incompletely but also accumulatively established, increasingly set in stone as the practical arrangements accrue. Verbal but not yet legal, real but not yet actual, to be engaged to be virtually married, a plane of action which inherently parallels the incomplete worlds of fiction itself.

Abortive engagement plots such as the one at the centre of The Small House, between Lily and Crosbie, reflect this narrative interest of Trollope's in weakening or circumventing conclusions; a type of story peculiarly suited to his writing process but about which, as a mode of behaviour for characters, he also appears ambivalent. Like Mrs Dale's relocating subplot, Can You Forgive Her? shows the novel in the process of working out whether its heroine still has room to manoeuvre. Alice breaks her engagement to John Grey in favour of her cousin George, but rather than any affirmation about the value of either partner, the narrative focuses on the ever-narrowing possibilities of escape from the 'moral barriers' guarding commitment:

She began to be aware that she was about to be guilty of a great iniquity, when it was too late for her to change her mind. She could not bring herself to resolve that she would, on the moment, change her mind. She believed that she could never pardon herself such weakness. But yet she felt herself to be aware that her purpose was wicked. ${ }^{68}$

The paragraph not only reproduces the novel in miniature - just as the story ultimately returns Alice to her original engagement with Grey, the fourth sentence here loops back onto the first with her dawning self- 
awareness - but also its toning down or subtle adjustment of the situation. The sentences do not exactly follow from each other, nor are they directly contradictory, but gradually reframe what exactly Alice is unable to do. In the first sentence, Alice cannot change her mind, because 'it is too late' to do so; in the second, she still cannot change her mind, but due to a lack of 'resolve' rather than practical possibility; her inability becomes entirely different in the third sentence, a hypothetical wherein she has already changed her mind but cannot 'pardon' herself for doing so. The wicked purpose of the fourth sentence becomes strongly ambiguous: referring either to the 'great iniquity' of jilting Grey, of which Alice 'began to be aware' in the first sentence, or to another guilty consciousness, developing through the free indirect discourse of the paragraph, by which she is already edging her way back.

At the same time, it is exactly this process of 'casuistic ingenuity', escaping the dilemma by small extenuations, which Trollope indicts in Alice as her moral failing. Can You Forgive Her? is a title which explicitly mounts this as a casuistic challenge, both reprimanding and redeeming Alice for the habits of thought by which she both talks herself out of the right conclusion and then back into it. The Small House poses the same question less leniently with the figure of the male jilt, for whom the indictment is absolute. ${ }^{69}$ With more implied culpability than Alice, Adolphus Crosbie creatively talks himself out of his engagement to Lily because he is tempted by a self-serving alliance with the aristocratic De Courcy family:

He had said to himself a dozen times during that week that he never could be happy with Lily Dale, and that he never could make her happy. And then he had used the old sophistry in his endeavour to teach himself that it was right to do that which he wished to do [...] He had discussed the matter in this way within his own breast, till he had almost taught himself to believe that it was his duty to break off his engagement with Lily; and he had also almost taught himself to believe that a marriage with a daughter of the house of Courcy would satisfy his ambition[.] (SH 203-4, emphasis added)

Unlike for either Mrs Dale or Alice, the narration passes a harsh and explicit judgement on Crosbie for employing 'the old sophistry' which underlies the behaviour of all Trollope's characters. In an exemplification of casuistic self-deception, Crosbie teaches himself to disguise 'that which he wished to do' as that which 'was right to do' - closely following this dishonest adjustment, the narration provides what Wall describes as 'a full account of [Crosbie's] drift into perfidy [...] a study of the ways in which a man may persuade himself to revise his intentions' ${ }^{70}$ But on what basis is 
this account distinguishable, for one, from Mrs Dale; and for another, from the disingenuous logic of the narrative itself, thinking in lockstep with Alice about how to turn her situation around?

Although The Small House gestures towards a moral dichotomy between Crosbie's inconstancy and the Dales' collective 'steadfastness', on the level of their construction as fictions, the two are not so easy to separate. If we might appreciate Trollope's virtuosity at writing his characters into and out of tight corners, to think of an engagement as a logic puzzle about navigating barriers to exit is to take the perspective of the novel's proclaimed villain. Appallingly, Mrs Dale who 'almost confessed to herself that she repented of what she was doing' performs a style of thinking almost exactly like that of a man whom she believes to have caused harm and suffering to her family. They are at one point syntactically identical:

[Self-promotion] was the line of life into which he had fallen, and he confessed inwardly that the struggle to extricate himself would be too much for him [...] He had almost acknowledged to himself that he repented his engagement with Lilian Dale, but he still was resolved that he would fulfil it. He was bound in honour [...] Yes; he would sacrifice himself. As he had been induced to pledge his word, he would not go back from it. ( $\mathrm{SH}$ I 59 , emphasis added)

For Crosbie as (disturbingly) for Mrs Dale, the first step to unsettling the force of commitment is to acknowledge it as a necessity rather than a choice; for Trollope, restriction is only a prompt to creative agency. Here, both the commitment which binds him to Lily and the nature which would lead him to abandon her are too strong 'to extricate himself: so pledged that 'he would not go back' on the engagement, yet also 'too late now to remedy the ill effects of an early education' (I 59) that has shaped his character. As Sussman also notes of this passage, Crosbie 'alienate[s] his agency when he wishes to distance himself from decisions, ${ }^{7 \mathrm{I}}$ but this is clearly not an exclusive character trait in Trollope's narrative world; Lily's rejection of Johnny is a similar non-decision, a calculus of apparently inevitable conditions ('I should be disgraced [...] if I admitted', $S H$ 498). Such statements would also not be out of place in $A n$ Autobiography, catching an imaginative freedom between what one's nature makes 'necessary' and an act of 'binding myself down' ( $\left.A A_{33}\right)$.

Like his author, Crosbie constructs his situation as a set of conditions; like the novel, a more flexible narrative arises out of the apparently inevitable. It does not take long for the initial formulation of his dilemma to invert into its opposite - that he has already determined to abandon Lily and has only to follow it through, exactly as he had previously determined 
to follow through with the engagement. On having been led to declare his love for Alexandrina De Courcy, Crosbie returns to his room again to contemplate another unalterable situation:

$[\mathrm{N}]$ ow that he had told Lady Alexandrina he loved her [...] he was obliged to confess to himself that the die was cast.

As he thought of all this, there was not wanting to him some of the satisfaction of an escape. Soon after making that declaration of love at Allington he had begun to feel that in making it he had cut his throat. He had endeavoured to persuade himself that he could live comfortably with his throat cut in that way [...] But the self-immolation had not been completed, and he now began to think that he could save himself [...] he acknowledged at this moment, as he rose from his seat to dress himself, that the die was cast, and that it was open to him now to say what he pleased to Lady Alexandrina ( $\mathrm{SH}$ 205).

Crosbie's various convictions move in different directions in this passage even as he admits not to be so 'bound in honour' (I 59) to Lily after all, and achieves 'some of the satisfaction of an escape' from a provisional situation that after all 'had not been completed', he conversely commits to the belief about his character (the apparent inevitability of his unhappiness with Lily) and to a sense 'that the die was cast' on this new decision: 'there was the fact, and he found himself unable to contend against it' (204). Even as his hyperbolic metaphors of escaping 'selfimmolation', 'suicide', and having 'his throat cut' reveal the 'sacrifice' ( I 59) of marrying Lily to be not so irreversible after all, Crosbie is unable to acknowledge the agency he has already exercised in changing his mind. When his mind changes yet again - or on realising his mistake - he returns more literally to 'thoughts of self-destruction as the only means of escape' (222), describing his self-made trap as that of 'marry[ing] Lady Alexandrina; - that is, if I do not cut the whole concern, and my own throat into the bargain' (225).

Crosbie does not kill himself, but that he continually resorts to imagining this as his 'only means of escape' becomes emblematic of his case as a singular one in which, for once, a character is finally unable to extricate himself from a fixed situation. And it is on this basis of his inflexibility, rather than a continuing 'drift' of position, which seals his fate as the irredeemable villain of the novel; he cannot invent another explanation of his own actions, and the narrator will not collude with him (as they do with Alice or Mrs Dale) to do so. As he realises when his marriage to Alexandrina is finalised, 'The course was now before him, and he had no choice but to walk in it' (409). All Trollope's characters protest their 
powerlessness before circumstance, but only Crosbie manages so badly to trap himself beyond redemption.

The charges of Crosbie's 'perfidy', in these terms, is not sophistry but a failure at sophistry. If Trollope's 'internal revision' advances subtle adjustments which impose a new logic on established facts, as he himself admits, this is a performance which is not always successful, a danger which Crosbie embodies as a moral failure. Like many characters, Crosbie revises his intentions with new interpretations, 'contradicting one argument by another over and over again [...] teaching himself to think that this engagement of his was a misfortune' (SH I 59), but unlike others, his public statements are too visibly contradictory: for instance, he struggles to reconcile the fact 'It had been already settled that he was to spend his Christmas at Courcy; as it had been also settled that he was to spend it at Allington' (22I). He repeatedly attempts to edit the past, wishing first to 'have blotted out that visit to Courcy Castle from the past facts of his experience' (220), then retroactively claiming that he had been 'already half engaged' (224) to Alexandrina before his proposal to Lily. As the narrator intrudes to point out, 'The reader, however, will understand that this half-engagement was a fiction' (224), and implicitly, a more incompetent fiction than the unblotted and still agile narrative of the novel itself. Overcommitted to and overstretched between incompatible positions, unable to delete or convincingly revise past facts in the narrative, Crosbie fails precisely at De Quincey's evasive demurring or at Trollope's art of fiction, having 'rushed at the work as a rider rushes at a fence which he does not see [...] [and] encountered what, in hunting language, we call a cropper' ( $A A$ i i I). What these metatextual metaphors identify as Crosbie's real crime is not the making of excuses in itself, but the inability to make better excuses, having compromised himself beyond the possibility for reinvention.

Trollope's novels continually evaluate, as the narrative unfolds, whether it is still possible to construct a workable explanation of the characters' actions. Both the narrative and its characters are actively engaged in making excuses as they go along, fashioning a coherent rationale for their behaviour after surprising narrative turns which leave them in difficult situations. This is the reverse of how casuistry, and its manifestation through the realist novel, is ideally supposed to work in their shared aims at perspicuity: casuists rely 'on the expansive descriptive powers native to realistic narrative $[\ldots]$ the thought that the everyday needs careful study if its true nature and value are to be revealed', and through this careful empiricism, question 'whether that description is all that is relevantly true 
of me and my situation, or if it is, whether it should continue to be true of me [...] as it unfolds an assessment of my past and my future. ${ }^{72}$ But this is a model of realism's functions which has its alternative in the novel as fiction, whose native powers are not 'descriptive' but creative, interested in inventing realities rather than its 'careful study'. The casuistic questions which guide this mode of thinking may be, instead: what can be true of me or my situation? How can I reimagine the necessary facts of my past to fit a better vision of my future? What are the acceptable limits of my agency? How do I morally get away with it?

These questions about living well by living skilfully, about creative action rather than accurate knowledge, is an ethical perspective the novel can offer precisely because of its difference from history. If real causation and circumstances are not as flexible as fiction, we can nonetheless usefully respond to them as if they were. 'For Trollope', Ratcliffe argues, literary practices like editing are 'more than a career - it is also a habit of mind [...] an alternative understanding of how individuals might exist in time, and of the ways in which selves might resolve their contradictory urges'. ${ }^{73}$ An Autobiography recurrently demonstrates a sophist's creativity with small details to be Trollope's characteristic mode of self-narrativisation. When the publishers of The Cornhill required Framley Parsonage to begin serialisation before the novel had been completed, Trollope invented a caveat to a 'principle with me in my art, that no part of a novel should be published till the entire story was completed [...] But such a principle becomes a tyrant if it cannot be superseded on a just occasion [...] I can say, however, that I have never broken it since' ( $A A$ 90-9I). Readers, however, should understand this final claim as a fiction; textual evidence proves at least four other novels - Orley Farm, The Small House, Can You Forgive Her?, and The Belton Estate - to have been written during their serial runs. ${ }^{74}$ But much as principles might casuistically give way 'on a just occasion', the facts of the case might bend to accommodate the better story of a lone exception. Trollope had contrived this account of himself, but in doing so, demonstrates the value of fiction to producing a more malleable perspective on the world: not being the whole truth, the account nonetheless captures the significant features of the dilemma; without being an outright lie, it also expresses something about how he aspires to have acted. To 'live with' fiction in this way imagines life's events not merely as they were, but as they are still possible. 